\title{
Monitoramento de empreendimentos hidrelétricos na bacia do rio Tocantins, Brasil: o que aprendemos com os estudos das macrófitas aquáticas
}

\author{
Eliania Pereira Pinheiro * \\ Elineide Eugênio Marques \\ Solange de Fátima Lolis \\ Universidade Federal do Tocantins, Campus Palmas \\ Quadra 109 Norte, Avenida NS15, ALCNO-14, Plano Diretor Norte \\ CEP 77.001-090, Palmas - TO, Brasil \\ * Autor para correspondência \\ eliana.uft@gmail.com
}

Submetido em 29/11/2018

Aceito para publicação em 15/05/2019

\section{Resumo}

O presente trabalho teve como objetivo analisar os estudos ambientais e monitoramentos de plantas aquáticas em reservatórios de usinas hidrelétricas para discutir a respeito de uma política de manejo dessas comunidades para reservatórios existentes e futuros. Foram realizadas a revisão bibliográfica e a pesquisa documental, buscando as informações nos Estudo de Impacto Ambiental (EIA), monitoramentos de cada empreendimento hidrelétrico, livros, revistas, publicações avulsas, sites especializados e imprensa escrita, disponibilizadas na Internet ou em bibliotecas. Os documentos obtidos foram sistematizados e as informações organizadas cronologicamente por empreendimento considerando a área de abrangência dos estudos; metodologias de coleta, tempo e número de amostragem. Constatou-se que ainda existem dificuldades para o acesso a documentos em guarda de órgãos ambientais. Observou-se que os monitoramentos, principalmente no âmbito da Licença Ambiental de Operação, não estão sendo executados sistematicamente, deixando lacunas importantes em relação à composição e abundância de espécies, o que dificulta a comparação do comportamento destas ao longo do tempo. Os monitoramentos analisados empregaram diferentes métodos, o que influenciou nos resultados quando se busca a análise integrada desses estudos. É necessário criar procedimentos e definir metodologias no processo de licenciamento ambiental para sistematização dos estudos e monitoramentos, visando melhorar a acessibilidade e permitir a análise integrada dos dados.

Palavras-chave: Hidrelétrica; Licenciamento Ambiental; Manejo; Monitoramento

\section{Abstract}

Monitoring of hydroelectric projects in the Tocantins River basin, Brazil: what have we learned from studies of aquatic macrophytes. The objective of the present work was to analyze the environmental studies and monitoring of aquatic plants in reservoirs of hydroelectric plants to develop a policy for managing these communities for existing and future reservoirs. The literature review and documentary analysis were carried out in search of information on environmental impact assessments, monitoring of each hydroelectric 
project, books, magazines, special publications, specialized websites and written press, available on the Internet or in libraries. The documents obtained were systematized and the information organized chronologically per undertaking considering the study area, sampling method, time and sampling number. It was found that there is still great difficulty in accessing documents in the hands of environmental agencies. It was observed that monitoring, mainly under an environmental operating license, is not being carried out systematically, leaving important gaps regarding the composition and abundance of species, which makes it difficult to compare their behavior over time. For monitoring studies, different methods were used which influenced the results when an integrated analysis was sought. It is necessary to create procedures and define methods in the environmental licensing process for the systematization of studies and monitoring, to improve the accessibility and allow the integrated analysis of data.

Key words: Environmental Licensing; Hydropower; Management; Monitoring

\section{Introdução}

O licenciamento ambiental foi estabelecido nacionalmente por meio da Lei Federal ํㅜ 6.938/81, de 31 de agosto de 1981, que estabeleceu a Política Nacional de Meio Ambiente e definiu os princípios e objetivos que norteiam a gestão ambiental. Posteriormente, um conjunto de instrumentos vem sendo desenvolvido e atualizado por meio de resoluções do Conselho Nacional de Meio Ambiente (CONAMA), órgão também criado pela mesma Lei, com poder para estabelecer normas e regulamentos. A consagração dessa Lei e de seus respectivos instrumentos deu-se com a Constituição de 1988, por meio do artigo 225, no capítulo referente à Proteção ao Meio Ambiente (SAMPAIO, 2012).

O Sistema de Licenciamento Ambiental é o processo administrativo sistemático das consequências ambientais da atividade que se pretenda desenvolver, desde sua fase de planejamento, e das medidas adotadas para seu controle, por meio da emissão de três licenças sucessivas, Licença Prévia (LP), Licença de Instalação (LI) e Licença de Operação (LO), e pela verificação de restrições determinadas em cada uma delas. Inclui os procedimentos de acompanhamento das licenças concedidas, por meio da inspeção e verificação periódica realizada pelos órgãos ambientais (BRASIL, 2002).

Para o licenciamento de ações e atividades modificadoras do meio ambiente com impactos significativos, a legislação prevê a elaboração, pelo empreendedor, do Estudo de Impacto Ambiental - EIA e do respectivo Relatório de Impacto Ambiental RIMA, a serem apresentados para a obtenção da Licença Prévia. Conforme estabelecido pelo CONAMA, "cabe ao Ibama verificar o potencial de degradação do meio ambiente, definindo os estudos ambientais pertinentes ao respectivo processo de licenciamento da atividade ou empreendimento" (BRASIL, 1997, art. 3ํㅡㄹ parágrafo único).

O artigo 6ํ da Resolução 01/86 do CONAMA (BRASIL, 1986) prevê que o EIA deve conter uma elaboração de programa de acompanhamento e monitoramento dos impactos positivos e negativos indicando os fatores e parâmetros a serem considerados.

Esses programas de monitoramentos e acompanhamentos fazem parte do Projeto Básico Ambiental (PBA), documento que apresenta, detalhadamente, todas as medidas de controle e os programas ambientais propostos no EIA, incluindo os programas de monitoramento limnológico e de macrófitas aquáticas.

Diante do crescimento dos problemas ocasionados pelas comunidades de macrófitas aquáticas nos últimos anos com a criação dos grandes reservatórios, o Instituto Brasileiro do Meio Ambiente e dos Recursos Naturais Renováveis (IBAMA), entidade responsável pelo licenciamento ambiental federal, tem exigido condicionantes ambientais específicas que tratam dos monitoramentos de macrófitas aquáticas, as quais estabelecem: "Detalhar todos os Planos, Programas, Subprogramas e Medidas Mitigadoras e de Controle consignados no Estudo de Impacto Ambiental e nos demais documentos técnicos, incluindo necessariamente a metodologia, o responsável técnico e o cronograma físico de implantação"; e "Apresentar separadamente os Programas de Monitoramento da Qualidade da Água e de Monitoramento de Macrófitas Aquáticas." 
Diante da problemática atual a respeito do processo de colonização em reservatórios por essa vegetação aquática e suas possíveis consequências, surgiu a necessidade de pesquisar em documentos técnicos disponíveis sobre os empreendimentos, incluindo estudos de licenciamento, monitoramentos e outros estudos existentes na literatura realizados até hoje, analisando como esses documentos estão organizados e disponibilizados.

O presente trabalho teve como objetivo analisar os estudos ambientais e os monitoramentos de plantas aquáticas em reservatórios de usinas hidrelétricas para discutir a respeito de uma política de manejo dessas comunidades para reservatórios existentes e futuros.

\section{Material e Métodos}

O trabalho foi realizado por meio de uma revisão bibliográfica, incluindo a pesquisa documental. A pesquisa bibliográfica é uma fonte de pesquisa que é desenvolvida com base em material já elaborado, constituído principalmente de livros e artigos científicos. Segundo Gil (2002), a pesquisa documental é muito parecida com a bibliográfica. A diferença está na natureza das fontes. Enquanto a pesquisa bibliográfica se utiliza fundamentalmente das contribuições dos diversos autores sobre determinado assunto, a pesquisa documental vale-se de materiais que não receberam ainda um tratamento analítico, ou que ainda podem ser reelaborados de acordo com os objetos da pesquisa.

O desenvolvimento da pesquisa documental segue os mesmos passos da pesquisa bibliográfica. Apenas há que se considerar que o primeiro passo consiste na exploração das fontes documentais, que são em grande número. Existem, de um lado, os documentos de "primeira mão", que não receberam qualquer tratamento analítico (documentos oficiais, reportagens de jornal, cartas, contratos, diários, filmes, fotografias, Boletins de Ocorrência e outros) e, do outro lado, existem também aqueles que já foram processados, mas podem receber outras interpretações, como relatórios de empresas e tabelas estatísticas (GIL, 2006).

No caso deste trabalho, a pesquisa documental tratou de dados já processados, buscando as informações nos Estudos de Impacto Ambiental (EIA), nos monitoramentos de cada empreendimento hidrelétrico, em livros, revistas especializadas, publicações avulsas, sites especializados, imprensa escrita e eletrônica, publicações especializadas na internet ou em bibliotecas. E todos os trabalhos levantados referem-se à colonização de macrófitas aquáticas nas usinas hidrelétricas da calha do Rio Tocantins.

Os locais de busca para esses dados foram no acervo da Biblioteca da Universidade Federal do Tocantins (UFT), na Biblioteca Digital de Teses e Dissertações no Banco de Teses da Capes nas bases de dados do portal CAPES, periódicos, revistas e Internet, e nos órgãos federais e estaduais de licenciamento, monitoramento e agências reguladoras do setor elétrico como: IBAMA, Naturatins (TO), Semarh (GO), ANA e ANEEL, onde foram consultados documentos oficiais, relatórios, artigos originais e de revisão sobre o tema.

Para o levantamento de referências foi utilizado o meio eletrônico, ou seja, ocorreu por meio de revistas eletrônicas e do portal periódicos Capes, com o emprego de termos de busca para determinado empreendimento. A busca do assunto se deu por título contendo as seguintes palavras-chaves: "Colonização*de macrófita*" AND reservatórios, "macrófita*aquática*" AND bacia do rio Tocantins, "macrófita*aquática*" AND riqueza, "planta* aquática*" AND diversidade, "planta*aquática*" AND bacia do rio Tocantins, "macrófita*aquática*" AND impactos, "planta*aquática*" AND impactos, "macrófita*aquática*” AND reservatório Tucuruí, "macrófita*aquática*” AND reservatório Cana Brava, "macrófita*aquática*" AND reservatório Serra da Mesa, "macrófita*aquática*" AND reservatório Lajeado, "macrófita*aquática*" AND reservatório Peixe Angical, "macrófita*aquática*” AND reservatório Estreito, "macrófita*aquática*” AND reservatório São Salvador.

O símbolo asterisco (*) colocado no fim das palavras indica que qualquer terminação dessa palavra pode ser encontrada na busca, garantindo a inclusão de formas plurais. As aspas são utilizadas para que a ferramenta de busca considere as palavras como sendo uma frase e o uso do operador AND traz como resultado 
da pesquisa registros que possuam obrigatoriamente todas as palavras ligadas por esse operador. Assume-se que as buscas usando essas palavras-chave capturaram uma parte representativa dos artigos importantes para este estudo.

Para a busca dos documentos técnicos foram enviados ofícios para os órgãos públicos federais e estaduais solicitando os Estudos de Impactos Ambientais (EIA), Relatórios de Impactos Ambientais (RIMA) e os monitoramentos realizados em cada Usina Hidrelétrica da bacia do rio Tocantins (UHE).

O levantamento abrangeu um período de 20 anos $(01 / 01 / 1984$ a $31 / 12 / 2013)$ e o material selecionado inclui livros, artigos e imagens em qualquer idioma. Os documentos obtidos foram sistematizados e as informações organizadas cronologicamente por empreendimento, considerando área de abrangência dos estudos, metodologias de coleta utilizadas, tempo e número de amostragem.

\section{Resultados e Discussão}

Os estudos encontrados sobre colonização de macrófitas aquáticas na bacia do Tocantins incluem EIA/ RIMA, monitoramentos de macrófitas, monitoramentos limnológicos, artigos, dissertações, teses e capítulos de livros. Todos esses documentos foram encontrados nos órgão ambientais federais e estaduais (IBAMA-TO, IBAMA-GO, Naturatins-TO e SEMARH-GO) e através do meio eletrônico (internet).

Na busca feita no IBAMA-TO, foram localizados EIA/RIMA e relatórios de monitoramento das usinas hidrelétricas de Peixe Angical, São Salvador e Estreito. No IBAMA-GO, foram encontrados relatórios de monitoramento limnológicos das usinas hidrelétricas de Serra da Mesa e monitoramentos da usina Hidrelétrica de Cana Brava.

O órgão ambiental do estado de Goiás (SEMARHGO) informou que acompanhou todo o processo de licenciamento das usinas hidrelétricas de Serra da Mesa e Cana Brava, porém toda a documentação foi encaminhada para o IBAMA-GO. No órgão estadual do Tocantins, Naturatins, foi possível encontrar o EIA/
RIMA e o monitoramento da usina hidrelétrica de Luís Eduardo Magalhães (Lajeado).

Foram encontrados quatro Estudos de Impacto Ambiental e Relatórios de Impacto Ambiental (EIA/ RIMA) das Usinas Hidrelétricas de Lajeado, Peixe Angical, São Salvador e Estreito, 20 relatórios de monitoramento de macrófitas aquáticas, 68 relatórios de monitoramento limnológico, 10 artigos relacionados ao processo de colonização, duas dissertações, duas teses e dois capítulos de livros (Tabela 1).

A hidrelétrica de Tucuruí foi construída antes da criação do Conselho Nacional de Meio Ambiente (CONAMA), em 1981, quando os estudos de impacto ambiental ainda não eram uma exigência legal.

A partir da implantação das primeiras grandes usinas hidrelétricas brasileiras, com a constatação de seus efeitos indesejáveis e da crescente sensibilização em relação à conservação, a legislação ambiental, que começou a ser regulamentada no início da década de 1980, impõe a consideração dos efeitos sobre o ambiente, a internalização dos respectivos custos e o escrutínio social sobre as alternativas de aproveitamento do recurso natural em pauta. Em 1986, o CONAMA, por meio da Resolução n⿳0 1/1986, incluiu as barragens no rol de atividades potencialmente poluidoras e, como tal, sujeitas ao licenciamento ambiental para implantação (COMISSÃO MUNDIAL DE BARRAGENS, 1999), instruído com EIA/RIMA (BRASIL, 1986).

A UHE Tucuruí é, portanto, anterior a esse importante marco legal, uma vez que entrou em operação em 1984, e, portanto sua concepção, concessão para exploração pela ELETRONORTE e a sua efetiva implantação não levaram em conta, de forma explícita, os efeitos sobre o ambiente em sentido amplo.

No que se refere ao Licenciamento Ambiental, somente em 1998, foi regularizada a situação da Usina de Tucuruí, com a concessão pela Secretaria de Estado de Ciência e Tecnologia do Estado do Pará (SECTAM) da Licença de Instalação das onze turbinas principais e das duas auxiliares, além da Licença de Operação do próprio empreendimento (COMISSÃO MUNDIAL DE BARRAGENS, 1999). 
TABELA 1: Número de estudos de macrófitas aquáticas nos empreendimentos da Bacia Hidrográfica do Tocantins.

\begin{tabular}{|c|c|c|c|c|c|c|c|}
\hline Empreendimentos & EIA/RIMA* & $\begin{array}{l}\text { Monitoramento } \\
\text { de macrófitas* }\end{array}$ & $\begin{array}{l}\text { Monitoramento } \\
\text { limnológico** }\end{array}$ & Artigo* & Dissertação* & Tese* & Livro* \\
\hline Tucuruí & Não & & & 7 & 1 & 1 & \\
\hline Serra da Mesa & Não encontrado & & 11 & & & & 1 \\
\hline Lajeado & Sim & 1 & 7 & 2 & & 1 & \\
\hline Cana Brava & Não encontrado & 7 & 19 & & & & \\
\hline Peixe Angical & Sim & 5 & 13 & & & & \\
\hline São Salvador & Sim & 5 & 5 & & & & \\
\hline Estreito & Sim & 2 & 13 & & & & \\
\hline
\end{tabular}

EIA/RIMA*: Lajeado, Peixe Angical e São Salvador: ENGEVIX THEMAG Engenharia e gerenciamento Ltda; Estreito: CNEC Engenharia S.A. Monitoramentos de Macrófitas aquáticas*: Lajeado: Universidade Federal de São Carlos (UFSCar), Bianchini Jr. et al. (2006); Cana Brava: Borsari - Engenharia e Meio Ambiente Ltda e Oikos - Assessoria, Serviços e Planejamento Ambiental Ltda.; Peixe Angical: Life - Projetos Limnológicos; São Salvador: Ecosafe - Agricultura e Meio Ambiente SS Ltda; Estreito: Borsari - Engenharia e Meio Ambiente Ltda. Monitoramentos Limnológico*: Serra da Mesa: MULTIGEO - Mineração - Geologia - Meio Ambiente; Lajeado: LAMBIO - Laboratório de Microbiologia da UFT/Palmas e Visão Ambiental; Cana Brava: Naturae Consultoria Ambiental Ltda.; São Salvador: Socioambiental Consultores Associados e Life Projetos Limnológicos; Peixe Angical: Life Projetos Limnológicos; Estreito: Unitins. Artigo*: Tucuruí: Abdon e Meyer (1988), Novo et al. (1989), Costa et al. (1996), Pereira Filho (1998), Graciani e Novo (2003), Vasconcelos e Novo (2003) e Arraut et al. (2009); Lajeado: Carreiro (2009) e Lolis e Thomaz (2011). Dissertação*: Tucuruí: Fearnside (2002). Tese*: Tucuruí: Manyari (2007); Lajeado: Lolis (2008). Livro*: Serra da Mesa: Capítulo 14, Filippo (2003).

No entanto, Tucuruí apresentou vários problemas com a colonização de macrófitas aquáticas logo após o enchimento do seu reservatório, principalmente relacionados à saúde pública, com a proliferação de mosquitos causadores de malária e leishmaniose (COMISSÃO MUNDIAL DE BARRAGENS, 1999).

As primeiras atividades relacionadas ao acompanhamento e à identificação de macrófitas aquáticas ocorreram a partir de agosto de 1993 pelo Instituto Nacional de Pesquisa da Amazônia (INPA), sendo desenvolvido o projeto "Levantamento e Controle de Macrófitas Aquáticas" que, após o enchimento do reservatório, foi assumido pelo consórcio ENGEVIX-THEMAG (ELETRONORTE/ CONSÓRCIO ENGEVIX-THEMAG, 2000).

Foram encontrados sete trabalhos sobre colonização de macrófitas aquáticas na UHE de Tucuruí, listados na Tabela 2. Entre os trabalhos estão os relatórios dos estudos de caso feitos pelo Comitê Mundial de Barragens, da fase escopo em 1999, e o relatório final em 2000.

No relatório de 2000, foram apresentados dados sobre a colonização das macrófitas aquáticas no reservatório de Tucuruí, em um documento, de fevereiro de 1999, intitulado "Inventário da Comunidade de Macrófitas Aquáticas Flutuantes na UHE Tucuruí através de Imagens Orbitais". Os estudos encontrados sobre colonização de macrófitas em Tucuruí foram realizados por meio de imagens de satélite e, segundo Arraut et al. (2009), o interesse pelo mapeamento das macrófitas aquáticas a partir de dados de Sensoriamento Remoto (SR) deu-se mediante o aumento de mosquitos transmissores de malária e de outras doenças de veiculação hídrica no reservatório. Para mapear o crescimento dessas plantas de fevereiro de 1999, os autores usaram dados dos sensores Landsat - TM e determinaram que poderiam ocupar até $25 \%$ da área do reservatório no período da enchente.

Esses estudos também indicaram que a comunidade de plantas aquáticas do reservatório da UHE Tucuruí vem decrescendo exponencialmente ao longo dos anos. De 1986 para 2002, a área ocupada decresceu de $1.096 \mathrm{~km}^{2}$ para algo em torno de $4 \mathrm{~km}^{2}$, numa taxa de decaimento exponencial estimada entre 0,20 e 0,30 ao ano. Os gêneros citados como de maior ocorrência no reservatório foram Salvinia, Scirpus e Pistia stratiotes. Entretanto de fevereiro de 1999 na região do Igarapé Pucuruí, há 
ocorrência do gênero Eichhornia (ELETRONORTE/ CONSÓRCIO ENGEVIX-THEMAG, 2002).

A hidrelétrica de Serra da Mesa foi construída anos depois do enchimento de Tucuruí, sendo concluída em 1996. As informações disponíveis sobre macrófitas aquáticas nesse reservatório são raras e os estudos de EIA/RIMA não se encontravam mais disponíveis nos arquivos recentes do órgão ambiental em função do longo tempo transcorrido desde o enchimento do reservatório, há quase vinte anos. Os únicos documentos disponíveis, os monitoramentos limnológicos, não contemplaram o acompanhamento de macrófitas aquáticas.

Entre os estudos encontrados, um deles aborda a colonização de macrófitas aquáticas em Serra da Mesa, é o capítulo 14 do livro Ecologia e Manejo de Macrófitas Aquáticas, de Filippo (2003), o qual relata que os primeiros registros de macrófitas aquáticas ocorreram por volta de setembro de 1997, durante a formação do reservatório, quando a velocidade do enchimento do lago já havia diminuído e se tratava da colonização de duas espécies: Salvinia sp. e Pistia stratiotes. Posteriormente ao seu enchimento foi observada uma regressão dessas espécies.

Segundo Filippo (2003), vários fatores podem ter sido favoráveis para esse processo de colonização durante períodos do enchimento, como: ritmo de enchimento lento, aumento de nutrientes disponíveis, estabilidade meteorológica e densidade de fitomassa elevada; e os restritivos, como: ritmo de enchimento rápido, diluição de nutrientes, eventos meteorológicos frequentes e densidade de fitomassa baixa. O mesmo autor ressalta, ainda, que a devida caracterização de cada um desses fatores e sua análise integrada poderá auxiliar na avaliação prévia dos riscos de desenvolvimento maciço de macrófitas aquáticas em futuros empreendimentos.

A respeito da UHE de Lajeado, foi encontrado um monitoramento de macrófitas aquáticas realizado por Bianchini Jr. et al. (2010), de 2004 a 2007, registrando 38 espécies, e um levantamento realizado por Lolis (2008), de 2005 a 2006, registrando 50 espécies, e por Carreiro (2009), de 2007 a 2008, registrando 52 espécies. O monitoramento de macrófitas aquáticas no reservatório da UHE Lajeado foi realizado por meio de um convênio entre FAI/UFSCar, UFT e INVESTCO para a execução do projeto de pesquisa e desenvolvimento (P\&D) intitulado: Macrófitas aquáticas do reservatório da UHE Lajeado: Dinâmica de incidência e interferências nos usos múltiplos. Nesse monitoramento, realizado por meio do $\mathrm{P} \& \mathrm{D}$, as espécies que apresentaram maior distribuição foram: Salvinia auriculata e Oxycaryum cubense, principalmente nos braços do reservatório (BIANCHINI Jr. et al., 2006).

Diante dos estudos encontrados e descritos sobre o processo de monitoramento de macrófitas aquáticas na UHE Lajeado, observa-se que os números de espécies são bem maiores nos trabalhos realizados por Lolis (2008) e Carreiro (2009), refletindo assim o maior esforço amostral, bem como uma área mais abrangente no trabalho realizado pelas autoras.

A hidrelétrica de Cana Brava foi licenciada pelo SEMARH, mesmo órgão Estadual de Goiás que licenciou a UHE Serra da Mesa. No órgão, não foi possível encontrar EIA/RIMA de Cana Brava, porém ela possui relatórios limnológicos e monitoramentos de macrófitas aquáticas.

Os relatórios limnológicos encontrados foram realizados a partir de julho 2005, já na fase de operação da hidrelétrica, até fevereiro de 2009, todos de responsabilidade da empresa de Consultoria Ambiental Naturae, com sede em Goiânia (GO). Os relatórios de monitoramento de macrófitas aquáticas foram iniciados em fevereiro de 2003 até setembro de 2009, os dois primeiros monitoramentos foram responsabilidade da empresa de consultoria OIKOS, com sede em Jaboticabal (SP), os demais, responsabilidade da Borsari Engenharia, também com sede em Jaboticabal (SP). As principais espécies encontradas no reservatório da UHE Cana Brava foram: Chara rusbiana, Nitella difusa, Salvinia auriculata, Utricularia gibba, Pistia stratiotes, Typha angustifolia, Brachiaria mutica, Bulbostyllis capilaris, Utricullaria gibba, Cyperus spp., Ludwigia spp., Lemna sp., Commelina difusa, Panicum repens, Paspalum repens e Brachiaria subquadripara.

A hidrelétrica de Peixe Angical aborda o monitoramento de macrófitas aquáticas dentro dos relatórios limnológicos, sendo os estudos produzidos 
conjuntamente em um único programa de monitoramento. Segundo a licença ambiental, o Programa de Monitoramento de Macrófitas Aquáticas atende às condicionantes específicas 2.1 e 2.7 da LP n 337/2009, IBAMA, que estabelecem: "Detalhar todos os Planos, Programas, Subprogramas e Medidas Mitigadoras e de Controle consignados no Estudo de Impacto Ambiental e nos demais documentos técnicos, incluindo necessariamente a metodologia, o responsável técnico e o cronograma físico de implantação"; e "Apresentar separadamente os Programas de Monitoramento da Qualidade da Água e de Monitoramento de Macrófitas Aquáticas".

A UHE Peixe Angical apresentou cinco relatórios de macrófitas aquáticas e 13 relatórios limnológicos (Tabela 2). As principais espécies encontradas no monitoramento de macrófitas aquáticas após a licença de operação foram Egeria najas e Nitella sp.

Os estudos encontrados da UHE São Salvador incluem EIA/RIMA, monitoramentos limnológicos e o plano de manejo de macrófitas aquáticas. O plano de manejo de macrófitas aquáticas possui relatórios de monitoramentos feitos nas fases pré-enchimento e pós-enchimento. As espécies que mostraram maior distribuição na região do reservatório após o seu enchimento foram: Najas conferta, Bulbostylis capilaris, Chara sp., Echinochloa polystachya, Lemna sp., Panicum repens, Cyperus ferax, Cyperus lusulae, Eleocharis minima, Hymenachne amplexicaulis, Polygonum lapathifolium e Salvinia auriculata.

A hidrelétrica de Estreito é o empreendimento mais recente, possui EIA/RIMA, monitoramentos de

TABELA 2: Referências dos estudos de macrófitas aquáticas nos empreendimentos da Bacia Hidrográfica do Tocantins.

\begin{tabular}{|c|c|c|c|c|c|c|c|}
\hline Empreendimentos & EIA/RIMA* & $\begin{array}{l}\text { Monitoramento } \\
\text { de macrófitas* }\end{array}$ & $\begin{array}{l}\text { Monitoramento } \\
\text { Llimnológico* }\end{array}$ & Artigo* & Dissertação* & Tese* & Livro* \\
\hline Tucuruí & & & & $\begin{array}{c}\text { Abdon e Meyer (1988) } \\
\text { Novo et al. (1989) } \\
\text { Costa et al. (1996) } \\
\text { Pereira Filho (1998) } \\
\text { Graciani e Novo (2003) } \\
\text { Vasconcelos e Novo } \\
\text { (2003) } \\
\text { Arraut et al. (2009) }\end{array}$ & $\begin{array}{l}\text { Fearnside } \\
\quad(2002)\end{array}$ & $\begin{array}{l}\text { Manyari } \\
(2007)\end{array}$ & \\
\hline Serra da Mesa & & & $\begin{array}{l}\text { Multigeo }(2005)^{*} \\
\text { Multigeo }(2006)^{*}\end{array}$ & & & & $\begin{array}{l}\text { Capítulo 14, } \\
\text { Filippo (2003) }\end{array}$ \\
\hline Lajeado & $\begin{array}{l}\text { THEMAG } \\
(1995)^{*}\end{array}$ & $\begin{array}{l}\text { Bianchini Jr. et al. } \\
\text { (2006) }\end{array}$ & $\begin{array}{l}\text { Visão Ambiental } \\
(2011)^{*} \\
\text { Lambio }(2006) *\end{array}$ & $\begin{array}{c}\text { Carreiro (2009) } \\
\text { Lolis e Thomaz (2011) }\end{array}$ & & $\begin{array}{l}\text { Lolis } \\
(2008)\end{array}$ & \\
\hline Cana Brava & & $\begin{array}{l}\text { Borsari }(2006)^{*} \\
\text { Borsari }(2007)^{*} \\
\text { Borsari }(2008)^{*} \\
\text { Borsari }(2009)^{*} \\
\text { Oikos }(2004)^{*}\end{array}$ & $\begin{array}{l}\text { Naturae }(2004)^{*} \\
\text { Naturae }(2005)^{*} \\
\text { Naturae }(2006)^{*} \\
\text { Naturae }(2007)^{*} \\
\text { Naturae }(2009)^{*}\end{array}$ & & & & \\
\hline Peixe Angical & $\begin{array}{l}\text { THEMAG } \\
(2000)^{*}\end{array}$ & $\begin{array}{l}\text { Life }(2007)^{*} \\
\text { Life }(2008)^{*} \\
\text { Life }(2009)^{*} \\
\text { Life }(2011)^{*}\end{array}$ & $\begin{array}{l}\text { Life }(2007)^{*} \\
\text { Life }(2008)^{*} \\
\text { Life }(2009)^{*} \\
\text { Life }(2011)^{*}\end{array}$ & & & & \\
\hline São Salvador & $\begin{array}{l}\text { ENGEVIX } \\
(2004)^{*}\end{array}$ & $\begin{array}{l}\text { Ecosafe }(2009)^{*} \\
\text { Ecosafe }(2010)^{*} \\
\text { Ecosafe }(2011)^{*}\end{array}$ & $\begin{array}{l}\text { Socioambiental } \\
(2010)^{*} \\
\text { Life }(2007)^{*}\end{array}$ & & & & \\
\hline Estreito & $\begin{array}{l}\text { CNEC } \\
(2001)^{*}\end{array}$ & $\begin{array}{l}\text { Borsari (2010)* } \\
\text { Borsari (2012)* }\end{array}$ & $\begin{array}{l}\text { Unitins (2010)* } \\
\text { Unitins (2011)* }\end{array}$ & & & & \\
\hline
\end{tabular}

* Referências de documentos técnicos que só se encontram nos órgãos ambientais. 
macrófitas aquáticas e monitoramentos limnológicos. O monitoramento de macrófitas aquáticas foi realizado também em duas fases, pré-enchimento e pósenchimento, porém realizados por empresas diferentes. $\mathrm{Na}$ fase de pré-enchimento, o monitoramento foi realizado pela Fundação Universidade Estadual do Tocantins (UNITINS), posteriormente, na fase pósenchimento, o monitoramento foi realizado pela empresa de Consultoria Ambiental Borsari Engenharia e Meio Ambiente, com sede em Jaboticabal (SP). No levantamento realizado após a LO, as principais espécies encontradas foram Ludwigia helminthorrhiza, Nymphoides indica, Carex spp., Oxycarium cubense, Rynchospora aurea, Brachiaria subquadripara, Salvinia auriculata, Lemna sp., Pistia stratiotes e Ceratopteris pteridoides.

Todos esses documentos foram analisados com o objetivo de encontrar informações sobre o processo de colonização de macrófitas aquáticas nos reservatórios, visando à identificação de padrões temporais que possibilitem a previsão para outros empreendimentos. Diante disso, os documentos que mais contribuíram com essas informações foram os monitoramentos, por meio destes foi possível levantar as espécies que colonizaram os reservatórios ao longo do tempo.

O Programa de Monitoramento de Macrófitas Aquáticas atende aos requisitos legais da Política Nacional de Recursos Hídricos (Lei no 9.433/1997) no que tange ao controle da poluição e ao enquadramento dos corpos de água em classes, segundo os usos preponderantes de água, entre outras medidas para manutenção da qualidade da água.

Segundo condicionantes do IBAMA, o monitoramento de macrófitas aquáticas tem como objetivo geral mensurar as modificações na macroflora aquática da área de influência da UHE advindas das transformações do ambiente, decorrentes da implantação e operação do empreendimento, e subsidiar a adoção de medidas de controle, caso sejam identificados problemas de proliferação excessiva de espécies indesejáveis.

Diante disso, o monitoramento de macrófitas aquáticas começou a fazer parte dos estudos de controle referentes aos impactos advindos de hidrelétricas, nos quais o objetivo é diagnosticar problemas de colonização excessiva dessas comunidades de plantas aquáticas nesses ambientes.

Contudo, os estudos levantados sobre as plantas aquáticas mostraram que os monitoramentos são realizados de forma diferente de um empreendimento para outro e que nem todas as hidrelétricas possuem plano de manejo de macrófitas aquáticas. A Tabela 3 mostra como os estudos de monitoramentos estão apresentados cronologicamente, por empreendimento, a partir de seu enchimento.

Os empreendimentos mais antigos não mencionam os estudos de macrófitas aquáticas ou realizam o acompanhamento desse grupo de modo irregular ao longo do tempo, a exemplo de Tucuruí. Contudo, mesmo em empreendimentos mais recentes, o acompanhamento

TABELA 3: Estudos e monitoramentos de macrófitas aquáticas realizados pelos empreendimentos.

\begin{tabular}{|c|c|c|c|c|c|c|c|c|c|c|c|c|c|c|c|c|c|c|c|c|c|}
\hline \multirow{2}{*}{ Usina } & \multirow{2}{*}{ Ano } & \multicolumn{20}{|c|}{ Tempo decorrido desde o enchimento (ano) } \\
\hline & & 1 & 2 & 3 & 4 & 5 & 6 & 7 & 8 & 9 & 10 & 11 & 12 & 13 & 14 & 15 & 16 & 17 & 18 & 19 & 20 \\
\hline Tucuruí & 1984 & & $X$ & & X & & & & & & $X$ & & & & & $X$ & $X$ & $X$ & $X$ & & \\
\hline Serra da Mesa & 1996 & & & & & & & & & & & & & & & & & & & & \\
\hline Lajeado & 2001 & & & & $\mathrm{X}$ & $\mathrm{X}$ & $\mathrm{X}$ & $\mathrm{X}$ & & & & & & & & & & & & & \\
\hline Cana Brava & 2002 & $\mathrm{X}$ & $\mathrm{X}$ & $\mathrm{X}$ & $\mathrm{X}$ & $\mathrm{X}$ & $\mathrm{X}$ & $\mathrm{X}$ & & & & & & & & & & & & & \\
\hline Peixe Angelical & 2006 & $\mathrm{X}$ & $\mathrm{X}$ & $\mathrm{X}$ & & $\mathrm{X}$ & & & & & & & & & & & & & & & \\
\hline São Salvador & 2009 & $\mathrm{X}$ & $X$ & $X$ & $X$ & & & & & & & & & & & & & & & & \\
\hline Estreito & 2010 & & & X & X & & & & & & & & & & & & & & & & \\
\hline
\end{tabular}


desse grupo tem sido realizado de modo irregular. Os relatórios de monitoramento relacionam estudos realizados nas UHE Cana Brava, Peixe Angical e São Salvador a partir do primeiro ano de enchimento, o que não ocorreu para as UHE Estreito e Lajeado, conforme mostra a Tabela 3 .
Além disso, a metodologia utilizada nas amostragens de campo e a periodicidade das coletas são muito variáveis e dificultam a comparação das informações (ver Tabela 4).

Todos os processos de monitoramento descritos acima, realizados pelos empreendimentos logo após a

TABELA 4: Metodologias utilizadas e conclusões dos trabalhos de monitoramentos de macrófitas aquáticas.

\begin{tabular}{|c|c|c|c|}
\hline \multicolumn{4}{|c|}{ Estudos de monitoramento de macrófitas aquáticas após enchimento } \\
\hline Empreendimento & Metodologias utilizadas & Conclusão & Empresa contratada \\
\hline Tucuruí & $\begin{array}{l}\text { Monitoramento dos bancos de macrófitas aquáticas por } \\
\text { meio de interpretação de imagens dos satélites Landsat5 } \\
\text { - Thematic Mapper - e Landsat } 7 \text { - Enhanced Thematic } \\
\text { Mapper - referentes ao período } 1986 \text { a } 2002 \text {. }\end{array}$ & $\begin{array}{l}\text { Redução na comunidade de macrófitas } \\
\text { aquáticas flutuantes ao longo dos anos. }\end{array}$ & $\begin{array}{l}\text { ENGEVIX- } \\
\text { THEMAG }\end{array}$ \\
\hline Serra da Mesa & - & - & - \\
\hline Lajeado & $\begin{array}{l}\text { Os métodos utilizados para o cumprimento da pesquisa } \\
\text { inclúram sobrevoos (que abrangeram todo o reservatório } \\
\text { e tributários, desde a barragem até o Município de } \\
\text { Brejinho de Nazaré), inspeções por barco e por terra. }\end{array}$ & $\begin{array}{l}\text { O monitoramento mostrou que as áreas } \\
\text { ocupadas pelas macrófitas aquáticas nesse } \\
\text { reservatório têm-se mantido praticamente } \\
\text { constantes desde as primeiras avaliações } \\
\text { (média: } 3,7 \% \text { ), corroborando a hipótese de } \\
\text { que essa comunidade esteja em equilíbrio. }\end{array}$ & $\begin{array}{l}\text { Universidade Federal } \\
\text { de São Carlos } \\
\text { (UFSCar) Bianchini } \\
\text { Jr. et al. (2010) }\end{array}$ \\
\hline Cana Brava & $\begin{array}{l}\text { A Borsari Engenharia realizou o levantamento de } \\
\text { macrófitas aquáticas utilizando um barco, pelo qual } \\
\text { percorreram toda a região do reservatório e tributários, } \\
\text { incluindo } 112 \text { pontos de amostragem distribuídos } \\
\text { aleatoriamente. Oikos Ltda. realizou a avaliação das } \\
\text { espécies de macrófitas infestantes utilizando uma lancha } \\
\text { para percorrer todo o reservatório, onde foram marcados } \\
\text { pontos com GPS } 254 \text {. Esses pontos foram demarcados } \\
\text { a, aproximadamente, } 3 \text { e } 4 \mathrm{~km} \text { de distância um do outro. }\end{array}$ & $\begin{array}{l}\text { Com os sete anos de monitoramento } \\
\text { concluiu-se que o reservatório de Cana } \\
\text { Brava tende a ser pressionado de tempos } \\
\text { em tempos quanto ao surgimento de algas e } \\
\text { macrófitas aquáticas. As condições históricas } \\
\text { e atuais da ocupação das macrófitas indica } \\
\text { que esse será um processo de longo prazo, } \\
\text { que deve ser avaliado e monitorado. }\end{array}$ & $\begin{array}{l}\text { Borsari - Engenharia } \\
\text { e Meio Ambiente } \\
\text { Ltda. Oikos - } \\
\text { Assessoria, Serviços } \\
\text { e Planejamento } \\
\text { Ambiental Ltda. }\end{array}$ \\
\hline Peixe Angical & $\begin{array}{l}\text { Para obtenção do levantamento das macrófitas aquáticas } \\
\text { utilizou-se um barco para percorrer todos os pontos de } \\
\text { amostragem do reservatório e tributários, pelo qual foi } \\
\text { utilizado um rastelo para verificar a existência de macrófitas } \\
\text { aquáticas submersas. O monitoramento de macrófitas } \\
\text { aquáticas foi realizado com o monitoramento limnológico, } \\
\text { foram } 14 \text { pontos amostrados até o enchimento do } \\
\text { reservatório, acrescentando posteriormente mais } 8 \text { pontos. }\end{array}$ & $\begin{array}{l}\text { De maneira geral, i) deve-se acompanhar } \\
\text { periodicamente o desenvolvimento desses } \\
\text { bancos de macrófitas e ii) deve-se, frequen- } \\
\text { temente, verificar se a vegetação aquática } \\
\text { encontra-se em zonas afastadas do corpo } \\
\text { central do reservatório, fato que dificulta o } \\
\text { transporte de grandes quantidades de vegetais, } \\
\text { através de correntes, na direção da barragem. }\end{array}$ & $\begin{array}{l}\text { Life - Projetos } \\
\text { Limnológicos }\end{array}$ \\
\hline São Salvador & $\begin{array}{l}\text { O reservatório da UHE São Salvador foi percorrido } \\
\text { de barco em toda a extensão de suas margens, com o } \\
\text { objetivo de identificar as plantas aquáticas presentes. } \\
\text { No caso das plantas de hábito submerso foi utilizado um } \\
\text { gancho amarrado a uma corda para coleta das plantas } \\
\text { em profundidade. Os espécimes foram identificados em } \\
\text { nível de espécie ou gênero, conforme a presença ou não } \\
\text { de órgãos reprodutivos (flores ou inflorescências). }\end{array}$ & $\begin{array}{l}\text { Com os monitoramentos, concluiu-se } \\
\text { que a única ocorrência que preocupa no } \\
\text { reservatório de São Salvador é a explosão } \\
\text { populacional de Salvínia. Essa macrófita } \\
\text { aquática é típica de reservatórios jovens, } \\
\text { mas seu crescimento pode causar problemas } \\
\text { à geração de energia elétrica. }\end{array}$ & $\begin{array}{l}\text { Ecosafe - Agricultura } \\
\text { e Meio Ambiente SS } \\
\text { Ltda. }\end{array}$ \\
\hline Estreito & $\begin{array}{l}\text { Foram percorridos } 21 \text { pontos de amostragem na } \\
\text { regiãocentral e marginal do reservatório. O percurso } \\
\text { foi feito de barco de alumínio e as macrófitas aquáticas } \\
\text { submersas foram avaliadas com o apoio de uma poita } \\
\text { tipogarateia de quatro pontas, que era lançada em várias } \\
\text { direções a partir do barco a uma distância de } 10 \mathrm{~m} \text {. }\end{array}$ & $\begin{array}{l}\text { O programa de monitoramento das } \\
\text { macrófitas aquáticas é inicial e deve ser } \\
\text { contínuo e de caráter preventivo, indicando } \\
\text { infestações e ações antes do nível de dano } \\
\text { econômico, ambiental e social. }\end{array}$ & $\begin{array}{l}\text { Borsari - Engenharia } \\
\text { e Meio Ambiente } \\
\text { Ltda. }\end{array}$ \\
\hline
\end{tabular}


LO, mostraram como as metodologias foram organizadas (Tabela 4) e como as próprias empresas de execução dos projetos concluíram seus estudos, apontando a necessidade de dar continuidade aos estudos de acompanhamento das comunidades de macrófitas aquáticas.

A maioria dos monitoramentos foi realizada pela iniciativa privada, as empresas contratadas para a realização dos estudos são de diferentes naturezas e o dado primário coletado é de difícil acesso. Além do mais, nos documentos analisados, não há indicação de onde o material botânico foi depositado, dificultando o acompanhamento ao longo do tempo.

Empresas de consultoria, sem ligações com instituições de pesquisa, não têm o compromisso de depositar o material coletado em coleções científicas, o que dificulta a checagem das informações apresentadas. Entre as empresas responsáveis pelos estudos, geralmente os primeiros monitoramentos foram realizados por instituições de pesquisa. Em Tucuruí, os primeiros estudos foram realizados pelo INPA e, após o enchimento, pela ENGEVIX-THEMAG. Nas UHE Serra da Mesa por Filippo (2003) e Lajeado pela UFSCar e UFT. Na UHE Peixe Angical por Borsari Engenharia e Oikos e na UHE São Salvador por Escosafe.

Por outro lado, os estudos realizados nas UHE Cana Brava e Estreito foram realizados exclusivamente por empresas de consultoria e, neste caso, o acesso às informações primárias, assim como o depósito do material botânico coletado, é muito mais difícil. O ideal seria a estruturação de um banco de dados com coletas padronizadas, registro de espécies, biomassa e depósito do material científico coletado, o que facilitaria o acompanhamento das modificações ocorridas ao longo do tempo, a análise temporal e a obtenção de modelos preditivos para outros empreendimentos ou bacias.

Durante análise desses estudos de monitoramentos, várias falhas foram identificadas nas variáveis analisadas: descrição dos métodos de levantamentos utilizados, qualidade dos métodos de levantamentos utilizados e a quantidade de espécies identificadas. Segundo Thomaz et al. (2007), os estudos das macrófitas aquáticas estão baseados, principalmente, em análises comparativas. Torna-se evidente, portanto, a necessidade de padronização mínima dos métodos e técnicas para obtenção de dados a serem posteriormente comparados.

Além da falta de padronização dos estudos, eles ainda são descontinuados, ou seja, todos os empreendimentos apresentaram falta de padronização entre os documentos, metodologias diferenciadas e falta de acompanhamento e continuidade dos estudos.

A descontinuidade dos monitoramentos, a dificuldade de acesso a essas informações e a esses estudos técnicos dificultam o acompanhamento dos processos de colonização e previsão para os novos empreendimentos. Contudo, o monitoramento é sumamente importante para o controle dessas comunidades de plantas, uma vez que a colonização em maior grau causa prejuízos à produção de energia $\mathrm{e}$ aos usos múltiplos do reservatório. É pensando nisso e nos futuros empreendimentos que surge, cada dia mais, a necessidade de preservar os dados e bibliografias existentes, pois os estudos podem ricamente ajudar no entendimento de problemas futuros e na previsão de controle não só de comunidades de macrófitas aquáticas, mas de comunidades aquáticas em geral.

Diante disso, é sugerido que a coleta periódica de dados e os levantamentos de espécies de macrófitas aquáticas proporcionam um melhor conhecimento dos sistemas aquáticos, constituindo hoje importantes ferramentas para verificar possíveis modificações, avaliar a qualidade da água e contribuir com propostas de preservação, controle de uso e recuperação desses ambientes (LANCAR; KRAKER, 2002; POMPÊO; MOSCHINI-CARLOS, 2003; TUNDISI, 2003; TAVARES, 2007).

A legislação ambiental vigente deve procurar melhorar o detalhamento do monitoramento das macrófitas, contemplando a padronização da metodologia a ser seguida, o número e a distribuição de pontos de amostragens em áreas de influência direta do reservatório, tributários, e em todo o corpo do reservatório, a listagem de todas as espécies levantadas antes e depois do represamento, o depósito do material em coleção científicas e outros, sem, no entanto, minimizar outras possibilidades de análise para responder a questões específicas de cada empreendimento. 
Os prejuízos financeiros e políticos ocasionados pela proliferação intensa de plantas aquáticas em reservatórios podem ser substancialmente reduzidos com a implementação de amplo programa de monitoramento com ênfase na detecção do crescimento e no manejo de macrófitas aquáticas, subsidiando a tomada de decisão. É necessário também criar meios de sistematização desses documentos de licenciamento e monitoramentos pelo órgão expedidor da licença, pois ainda existe uma grande dificuldade de acesso a esses documentos. Alguns documentos foram perdidos ou estão indisponíveis, pois foram transferidos para depósitos de difícil acesso nos órgãos ambientais. $\mathrm{O}$ IBAMA, por exemplo, possui uma plataforma online para depósito desses dados, porém não havia dados disponibilizados para todas as hidrelétricas estudadas. Foram realizados EIA/RIMA para as UHE Cana Brava e Serra da Mesa, sendo que a última também executou monitoramentos limnológicos, porém nenhum desses documentos foram encontrados nos órgãos ambientais responsáveis.

Seria eficaz a alimentação contínua da plataforma online e que essa plataforma pudesse estar dentro do "Sistema Nacional de Informação sobre Meio Ambiente" (SINIMA), que integrasse numa só base todos os dados produzidos perante os órgãos do SISNAMA. O SINIMA é um dos instrumentos da Política Nacional do Meio Ambiente que ainda não foi devidamente implementado (BRASIL, 1981).

Como os dados de monitoramentos são de interesse coletivo, devem ser publicitados pelo poder público em meio digital pela internet (BRASIL, 2003). Tratase de dados de grande importância ambiental, que podem ser utilizados para previsões futuras em outros empreendimentos e que não são organizados de forma sistematizada e eficaz para estudos posteriores. Além disso, seria importante a criação de uma biblioteca física para consulta dos documentos.

É necessário também padronização de metodologias a serem utilizadas nos monitoramentos, pois os monitoramentos analisados mostraram diferentes métodos. A forma diferenciada de metodologias influencia nos resultados quando se propõe uma análise integrada desses estudos. O investimento realizado no levantamento das informações de campo, que representa um esforço grande de coleta, recursos humanos e financeiros acabam subutilizados diante da (des)organização do sistema, que não oferece suporte adequado para sistematização e busca de informações.

\section{Referências}

ABDON, M. M.; MEYER, M. Variação temporal de áreas ocupadas por macrófitas aquáticas no Reservatório de Tucuruí através de dados do satélite Landsat/TM. In: SIMPÓSIO LATINOAMERICANO DE PERCEPCIÓN REMOTA. SAN CARLOS DE BARILOCHE, 4, 1988, Buenos Aires. Anais... Buenos Aires: SELLPER, 1988. Disponível em: <www.marte.sid.inpe.br>.

ARRAUT, E. M.; NOVO, F. M. L. M.; MANTOVANI, J. E. Um estudo do ciclo de vida e padrão espacial de bancos de macrófitas aquáticas por meio de uma série histórica de imagens Landsat-TM e ETM. In: SIMPÓSIO BRASILEIRO DE SENSORIAMENTO REMOTO, XIV, 2009, Natal. Anais... Natal: INPE, 2009. p. 12451251.

BIANCHINI Jr., I.; CUNHA-SANTINO, M. B.; FUSHITAB, A. T.; ALMEIDA, D. A.; MAIA, A. T. Monitoramento das macrófitas aquáticas do Reservatório da Usina Hidrelétrica Luís Eduardo Magalhães (estado de Tocantins, Brasil). 2006. Disponível em: $<$ www.ambiente-augm.ufscar.br/uploads/A2-013.doc>.

BIANCHINI Jr., I.; CUNHA-SANTINO, M. B.; MILAN, J. A. M.; RODRIGUES, C. J.; DIAS, J. H. P. Growth of Hydrilla verticillata (L.f.) Royle under controlled conditions. Hydrobiologia, Brussels, V. 644, p. 301-312, 2010.

BRASIL. Lei № 6.938, de 31 de agosto de 1981. Dispõe sobre a Política Nacional do Meio Ambiente, seus fins e mecanismos de formulação e aplicação, e dá outras providências. De 02 de setembro de 1981. Brasília: Diário Oficial [da] República Federativa do Brasil, 1981. Disponível em: <http://www.planalto. gov.br/ccivil_03/Leis/L6938>.

BRASIL - Ministério do Meio Ambiente. Conselho Nacional do Meio Ambiente (CONAMA). Resolução n⿳0 1 , de 23 de janeiro de 1986. Brasília: Diário Oficial [da] República Federativa do Brasil, 1986. Seção 1, p. 2548-2549. Disponível em: <http://www.mma. gov.br/port/conama/res/res86/res0186.html>.

BRASIL - MINISTÉRIO DO MEIO AMBIENTE. CONSELHO NACIONAL DO MEIO AMBIENTE (CONAMA). Resolução № 237, de 19 de dezembro de 1997. Brasília: Diário Oficial [da] República Federativa do Brasil, 1997. Disponível em: <http:// www.icmbio.gov.br/cecav/images/download/CONAMA $\% 20$ 237_191297.pdf>.

BRASIL - MINISTÉRIO DO MEIO AMBIENTE. Guia de procedimentos do Licenciamento Ambiental Federal. Documento de Referência. Brasília: MMA, 2002. 128 p.

BRASIL. Lei no $\mathbf{1 0 . 6 5 0}$, de 16 de abril de 2003. Dispõe sobre o acesso público aos dados e informações existentes nos órgãos e entidades integrantes do Sisnama. De 17 de abril de 2003. Brasília: Diário Oficial [da] República Federativa do Brasil, 2003. Disponível em: <http://www.planalto.gov.br/ccivil_03/Leis/L6938>. 
CARREIRO, Z. C. Variação temporal da composição de macrófitas aquáticas no reservatório da Usina Hidrelétrica Luis Eduardo Magalhães e espécies indicadoras de ambientes antropizado. 2009. 43 f. Dissertação (Mestrado em Ciências do Ambiente) - Universidade Federal do Tocantins, Palmas. 2009.

COMISSÃO MUNDIAL DE BARRAGENS. Usina Hidrelétrica de Tucuruí. Estudos de caso da CMB. Relatório final da fase de Escopo, Agosto, 1999. 42 p.

COSTA, M. P. F.; AHERN, F. J.; NOVO, E. M. L. M.; PIETSCH, R. W.; NOERRNBERG, M. A. Efeito dos dados de multipolarização SAR-C aero-transportado na separabilidade do retroespalhamento de plantas aquáticas do reservatório de Tucuruí - Amazônia. In: SIMPÓSIO BRASILEIRO DE SENSORIAMENTO REMOTO, VIII, 1996, Salvador. Anais... Salvador: INPE, 1996. Disponível em: $<$ http://marte.dpi.inpe.br/col/dpi.inpe.br/lise/2004/08.25.13.20/ doc/@sumario.htm>.

ELETRONORTE/CONSÓRCIO ENGEVIX-THEMAG. UHE Tucuruí, etapa final - Unidades 13 a 23, projeto executivo; dinâmica de plantas aquáticas no reservatório de Tucuruí; TUC-EMAN-805-0004-RE Tucuruí: Consórcio Engevix-Themag, 2000. 19 p.

ELETRONORTE/CONSÓRCIO ENGEVIX-THEMAG. UHE Tucuruí, etapa final - Unidades 13 a 23, projeto executivo; dinâmica de plantas aquáticas no reservatório de Tucuruí; TUC-EMAN-805-0010-RC. Tucuruí: Consórcio Engevix-Themag, 2002. $19 \mathrm{p}$.

FEARNSIDE, P. M. Impactos sociais da hidrelétrica de Tucuruí. Manaus: INPA, 2002. 27 p.

FILIPPO, R. Colonização e regressão da comunidade de macrófitas aquáticas no reservatório de UHE Serra da Mesa - Goiás. In: THOMAZ, S. M.; BINI, L. M. (Ed.). Ecologia e manejo de macrófitas aquáticas. Maringá: Eduem, 2003. p. 281-297.

GIL, A. C. Como elaborar projetos de pesquisa. 4. ed. São Paulo: Atlas, 2002. $176 \mathrm{p}$.

GIL, A. C. Métodos e técnicas de pesquisa social. 5. ed. São Paulo: Atlas, 2006. 220 p.

GRACIANI, S. D.; NOVO, E. M. L. M. Determinação da cobertura de macrófitas aquáticas em reservatórios tropicais. In: SIMPÓSIO BRASILEIRO DE SENSORIAMENTO REMOTO, XI, 2003, Belo Horizonte. Anais... Belo Horizonte: INPE, 2003. Disponível em: $<$ http://marte.sid.inpe.br/col/ltid.inpe.br/sbsr/2003/03.28.12.35/ doc/@sumario.htm>.

LANCAR, L.; KRAKE, K. Aquatic weeds \& their management. New Delhi: International Commission on Irrigation and Drainage, 2002. 65 p.
LOLIS, S. F. Macrófitas aquáticas do reservatório Luís Eduardo Magalhães - Lajeado - Tocantins: biomassa, composição da comunidade e riqueza de espécies. 2008. 91 f. Tese (Doutorado em Ciências Ambientais) - Universidade Estadual de Maringá, Maringá. 2008.

LOLIS, S. F.; THOMAZ, S. M. Monitoramento da composição específica da comunidade de macrófitas aquáticas no Reservatório Luis Eduardo Magalhães. Planta Daninha, Viçosa, v. 29, p. $247-$ 258, 2011.

MANYARI, V. W. Impactos ambientais a jusante de hidrelétricas. O caso da Usina de Tucurú, PA. 2007. 211 f. Tese (Doutorado em Planejamento Energético) - Universidade Federal do Rio de Janeiro, Rio de Janeiro. 2007.

NOVO, E. M. L. M.; HANSON, J. D.; CURRAN, P. J. The effect of sediment type on the relationship between reflectance and suspended sediment concentration. International Journal of Remote Sensing, Terre Haute, v. 10, n. 7, p. 1283-1289, 1989.

PEREIRA FILHO, W. Relações entre macrófitas aquáticas flutuantes e uso da terra, o caso do reservatório da UHE-Tucuruí. In: SIMPÓSIO BRASILEIRO DE SENSORIAMENTO REMOTO, IX, 1998, Santos. Anais... Santos: INPE, 1998. Disponível em: $<$ http://marte.sid.inpe.br/col/dpi.inpe.br/lise/2004/08.11.17.13/ doc/@sumario.htm>.

POMPÊO, M. L. M.; MOSCHINI-CARLOS, V. Macrófitas aquáticas e perifíton: aspectos ecológicos e metodológicos. São Carlos: RiMa Editora e FAPESP, 2003. 134 p.

SAMPAIO. R. Direito Ambiental. Rio de Janeiro: Fundação Getúlio Vargas, 2012. 171 p.

TAVARES, K. S. Caracterização limnológica e inventário de diversidade das comunidades de macrófitas aquáticas em cinco lagoas tropicais: composição florística, biomassa e macro invertebrados associados. 2007. 124 f. Tese (Doutorado em Ciências) - Universidade Federal de São Carlos, São Carlos. 2007.

THOMAZ, S. M.; BINI, L. M.; BOZELLI, R. L. Floods increase similarity among habitats in river-floodplain systems. Hydrobiologia, Brussels, v. 579, n. 1, p. 1-13, 2007.

TUNDISI, J. G. A bacia hidrográfica como laboratório experimental para o ensino de ciências, geografia e educação ambiental. In: SCHIEL, D.; MASCARENHAS, S.; VALEIRAS, N.; SANTOS, S. A. M. (Org.). O estudo de bacias hidrográficas: uma estratégia para educação ambiental. 2. ed. São Carlos: Rima, 2003. p. 3-8.

VASCONCELOS, C. H.; NOVO, E. M. L. M. Mapeamento de macrófitas e paliteiros do Reservatório de Tucurú (PA), utilizando imagens RADASAT. In: SIMPÓSIO BRASILEIRO DE SENSORIAMENTO REMOTO, XI, 2003, Belo Horizonte. Anais... Belo Horizonte: INPE, 2003. Disponível em: <http://marte.sid. inpe.br/col/ltid.inpe.br/sbsr/2002/11.14.17.31/doc/18_211.pdf $>$. 